ARTICLE

httpst//doi.org/10.1038/s41467-021-27507-x

\title{
Highly selective synthesis of all-carbon tetrasubstituted alkenes by deoxygenative alkenylation of carboxylic acids
}

Yantao $\mathrm{Li}^{1}$, Qianzhen Shao ${ }^{2,3}$, Hengchi He ${ }^{1}$, Chengjian Zhu ${ }^{1,4 凶}$, Xiao-Song Xue (i] ${ }^{2,3 凶} \&$ Jin Xie (i) ${ }^{1,5 凶}$

The synthesis of all-carbon tetrasubstituted olefins under mild reaction conditions is challenging because of the inevitable issues including significant steric hindrance and the uncontrolled $Z / E$ stereoselectivity. In this paper, we report the synthesis of all-carbon tetrasubstituted alkenes from readily available carboxylic acids and alkenyl triflates with the synergistic catalysis of cyclo-octa-1,5-diene(tetramethyl-1,4-benzoquinone)nickel and visible light under an air atmosphere, thus avoiding the need for a glovebox or a Schlenk line. A wide range of aromatic carboxylic acids and cyclic and acyclic alkenyl triflates undergo the $\mathrm{C}-\mathrm{C}$ coupling process smoothly, forming structurally diverse alkenes stereospecifically in moderate to good yields. The practicality of the method is further illustrated by the late-stage modification of complex molecules, the one pot synthesis and gram-scale applications. This is an important step towards the valuable utilization of carboxylic acids, and it also simplifies the experimental operation of metallophotoredox catalysis with moisture sensitive nickel(0) catalysis.

\footnotetext{
${ }^{1}$ State Key Laboratory of Coordination Chemistry, Jiangsu Key Laboratory of Advanced Organic Materials, Chemistry and Biomedicine Innovation Center (ChemBIC), School of Chemistry and Chemical Engineering, Nanjing University, Nanjing 210023, China. ${ }^{2}$ Key Laboratory of Organofluorine Chemistry, Shanghai Institute of Organic Chemistry, University of Chinese Academy of Sciences, Chinese Academy of Sciences, Shanghai 200032, China. ${ }^{3}$ State Key Laboratory and Institute of Elemento-Organic Chemistry, College of Chemistry, Nankai University, Tianjin 300071, China. ${ }^{4}$ State Key Laboratory of Organometallic Chemistry, Shanghai Institute of Organic Chemistry, Shanghai 200032, China. ${ }^{5}$ Advanced Catalytic Engineering Research Center of the Ministry of Education, Hunan University, Changsha 410082, China. 凶email: cjzhu@nju.edu.cn; xuexs@sioc.ac.cn; xie@nju.edu.cn
} 
T he construction of all-carbon tetrasubstituted alkenes has long been a challenge in organic chemistry due to the significant steric hindrance and the uncontrolled $Z / E$ stereoselectivity in the synthesis of such molecules ${ }^{1}$. The classical synthetic methods ${ }^{2-5}$, including Wittig olefination, Peterson olefination, Horner-Wadsworth-Emmons reaction, olefinsubstitution and elimination of water from alcohols, do not proceed well and can result in poor selectivity and efficiency when used in an attempt to construct linear tetrasubstituted alkenes. Transition-metal-catalyzed C-C coupling reactions or carbometalation of internal alkynes have recently been identified as powerful tools with which to realize such stereospecific transformations (Fig. 1a) ${ }^{6-17}$. However, in these reactions, organometallic reagents derived from $\mathrm{Zn}, \mathrm{Al}$, and $\mathrm{Mg}$ are required to improve the reaction efficiency, and in turn decrease the compatibility of the reaction system, and require that moisture must be scrupulously avoided. Thus, development of a robust and practical synthetic methodology to address the existing limitations to access all-carbon tetrasubstituted alkenes is highly desirable.

Thanks to the pioneering works of MacMillan, Doyle, and Molander ${ }^{18,19}$, photoredox-nickel dual catalysis has proved to be successful as an efficient and mild strategy for these reactions ${ }^{20-38}$. Very recently, we have achieved cross-electrophile $\mathrm{C}-\mathrm{C}$ coupling of aromatic acids and aromatic halides enabled by photoredox catalysis and nickel catalysis ${ }^{39}$. To the best of our knowledge, almost all the metallophotoredox catalyzed reactions require an inert reaction atmosphere, such as nitrogen or argon, and this requires use of a glovebox or the Schlenk technique. In 2020, Cornella and Engle independently reported two kinds of air-stable nickel(0)-olefin catalysts for Ni-catalyzed coupling ${ }^{40,41}$. Based on this point, we wondered if the synergistic photoredox and $\mathrm{Ni}(0)$ catalysis could be achieved under an air atmosphere. This technique has not been used to date but would greatly simplify the operation of metallophotoredox catalysis with nickel catalyst.

Carboxylic acids are commercially abundant, structurally diverse and generally stable feedstock chemicals commonly used in synthesis. With our continuing efforts in selective C-O bond functionalization of carboxylic acid ${ }^{39,42-44}$, we attempted to

a

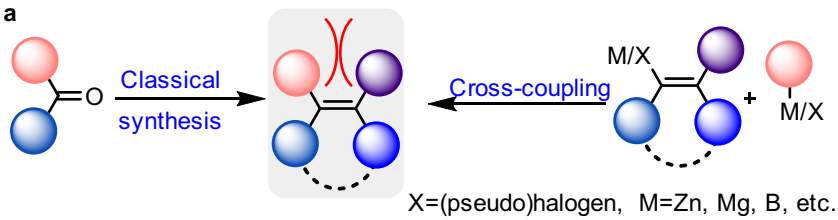

b

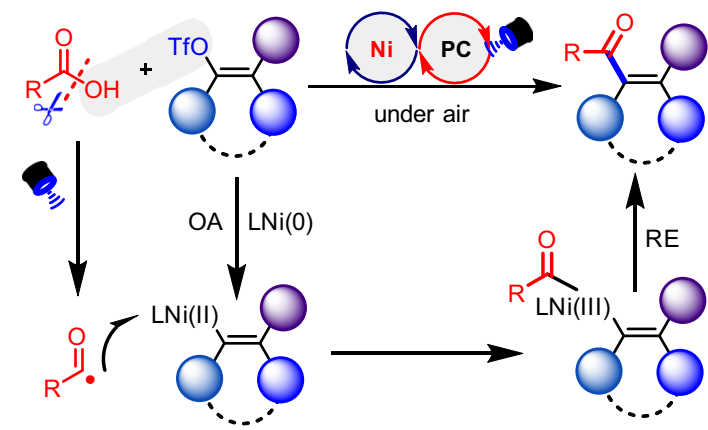

Simple operation under air Excellent stereoselectvity

Fig. 1 General strategies to access bulky alkenes. OA oxidative addition, $\mathrm{RE}$ reductive elimination. a Traditional methods to construct all-carbon tetrasubstituted olefins. b This work: Deoxygenative alkenylation of carboxylic acids. develop a practical strategy for the construction of all-carbon tetrasubstituted alkenes with a wide array of readily available cyclic and acyclic alkenyl triflates under air atmosphere (Fig. 1b). This reaction would be enabled by metallophotoredox catalysis using a photocatalyst and $\mathrm{Ni}(\mathrm{COD})(\mathrm{DQ})$ at room temperature without the involvement of organometallic reagents, in which the resultant acyl radical by photoredox catalysis would potentially add to $\mathrm{Ni}$ (II)-species to initiate the unprecedented C-C coupling for the synthesis of highly sterically congested ketones.

Here, we show a highly efficient metallophotoredox deoxygenative alkenylation of aromatic acids by means of $\mathrm{Ni}(\mathrm{COD})$ (DQ) under air conditions, constructing all-carbon tetrasubstituted alkenes from readily available starting materials.

\section{Results}

Reaction optimization. To initiate the study of cross-coupling used for the synthesis of all-carbon tetrasubstituted alkenes, 4-fluorobenzoic acid (1a) with ethyl 2-((trifluoromethyl)sulfonyl)oxy)cyclohex-1-ene-1-carboxylate (2a) were selected as a model reaction. The optimized reaction conditions (Table 1 ) were identified as $1 \mathrm{~mol} \% \quad\left[\operatorname{Ir}\left\{\mathrm{dF}\left(\mathrm{CF}_{3}\right) \text { ppy }\right\}_{3}\{\mathrm{dtbbpy}\} \mathrm{PF}_{6}, \quad 3 \mathrm{~mol} \%\right.$ $\mathrm{Ni}(\mathrm{COD})(\mathrm{DQ}), 5 \mathrm{~mol} \%$ 4,4'-di-methyl-2,2'-bipyridine (L1), 1.5 equiv $\mathrm{Ph}_{3} \mathrm{P}$, and 2.0 equiv $\mathrm{Na}_{2} \mathrm{CO}_{3}$ under blue LEDs in DMF. The reaction afforded $3 \mathbf{a}$ in $90 \%$ isolated yield under an air atmosphere (entry 1). When $\mathbf{L 2}$, or $\mathbf{L} 3$ was employed instead of $\mathbf{L} \mathbf{1}$, the yield was not improved (entries 2-3). The photocatalyst PC-2

Table 1 Optimization of the reaction conditions ${ }^{a}$.

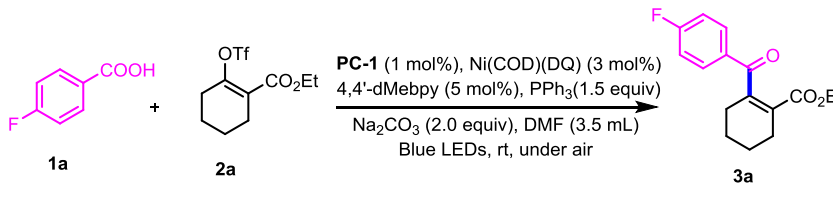

\begin{tabular}{|c|c|c|}
\hline Entry & Variation of standard conditions & Yield(\%) \\
\hline 1 & none & 90 \\
\hline 2 & $\mathbf{L 2}$ instead of $\mathbf{L 1}$ & 70 \\
\hline 3 & $\mathbf{L} \mathbf{3}$ instead of $\mathbf{L 1}$ & 60 \\
\hline 4 & PC-2 instead of PC-1 & Trace \\
\hline 5 & $\mathrm{MeCN}$ as solvent & Trace \\
\hline 6 & DCM as the solvent & ND \\
\hline 7 & THF as the solvent & 10 \\
\hline 8 & $\mathrm{Cs}_{2} \mathrm{CO}_{3}$ as base & 32 \\
\hline 9 & No $\mathbf{P C - 1}$ or $[\mathrm{Ni}]$ or $\mathrm{Ph}_{3} \mathrm{P}$ or light & ND \\
\hline & $\mathrm{PF}_{6}^{t}$ & $\begin{array}{l}\mathrm{R}=\mathrm{Me} \\
\mathrm{R}={ }^{\mathrm{t}} \mathrm{Bu} \\
\mathrm{R}=\mathrm{OMe}\end{array}$ \\
\hline
\end{tabular}

DMF $N, N$-dimethylformamide, ND not detected, $\mathrm{Ni}(C O D)(D Q)$ cyclo-octa-1,5diene(tetramethyl-1,4-benzoquinone)nickel.

aStandard conditions: PC-1 (1 mol\%), Ni(COD)(DQ) (3 mol\%), L1 (5 mol\%), 1a $(0.2 \mathrm{mmol}), \mathbf{2 a}$ $(0.3 \mathrm{mmol}), \mathrm{Ph}_{3} \mathrm{P}(0.3 \mathrm{mmol}), \mathrm{Na}_{2} \mathrm{CO}_{3}(0.4 \mathrm{mmol}), \mathrm{DMF}(3.5 \mathrm{~mL})$, blue LEDs, under air atmosphere at ambient temperature, $24 \mathrm{~h}$.

blsolated yields. 
<smiles>CCOC1=C(C(=O)c2ccc(F)cc2)CCCC1</smiles>

3a, $90 \%$<smiles>CCOC(=O)C1=C(C(=O)c2ccccc2)CCCC1</smiles>

3b, $73 \%$<smiles>CCOC(=O)C1=C(C(=O)c2ccc(C)cc2)CCCC1</smiles>

3c, $63 \%$<smiles>CCOC(=O)C1=C(C(=O)c2ccc(C(C)(C)C)cc2)CCCC1</smiles>

3d, $65 \%$<smiles>CCOC1=C(C(=O)c2ccc(OC)cc2)CCCC1</smiles><smiles>CCOC(=O)C1=C(C(=O)c2ccc(S(C)(=O)=O)cc2)CCCC1</smiles>

3e, $63 \%$

3f, $65 \%$<smiles>CCOC(=O)C1=C(C(=O)c2ccc(-c3ccccc3)cc2)CCCC1</smiles>

$3 g, 75 \%$<smiles>CCOC(=O)C1=C(C(=O)c2ccc(O)cc2)CCCC1</smiles>

3h, $64 \%$<smiles>CCOC(=O)C1=C(C(=O)c2ccc(I)cc2)CCCC1</smiles>

3i, $74 \%$<smiles>[CH]</smiles><smiles>CCOC(=O)C1=C(C(=O)c2ccccc2)CCCC1</smiles><smiles>O=C(C1=C(C(Cl)=C(Cl)Cl)CCCC1)c1ccc(C2CCCCC2)cc1</smiles>

3k, $51 \%$<smiles>CCOC(OCC)C1=C(C(=O)c2cccc(Cl)c2)CCCC1</smiles>

3p, $50 \%$<smiles>CCOC(=O)C1=C(C(=O)c2cccc(OC(C)(C)C(=O)OC(C)C)c2)CCCC1</smiles>

3q, $60 \%$<smiles>CCOC(=O)C1=C(C(=O)c2cc(F)ccc2C)CCCC1</smiles>

3v, $78 \%$<smiles>COC(=O)C1=C(C(=O)c2cc(Cl)cc(OC)c2)CCCC1</smiles>

3w, $42 \%$<smiles>CCOC(=O)C1=C(C(=O)c2cccc(C(C)C#N)c2)CCCC1</smiles>

3I, $67 \%$<smiles>CCOC(=O)C1=C(C(=O)c2ccccc2C)CCCC1</smiles>

3s, $63 \%$<smiles>CCOC(=O)C1=C(C(=O)c2ccc(C)c(F)c2)CCCC1</smiles>

3y, $86 \%$

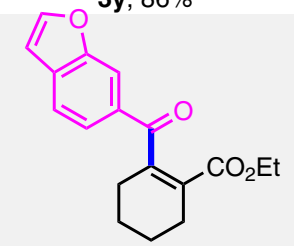

3dd, $61 \%$

3t, $70 \%$

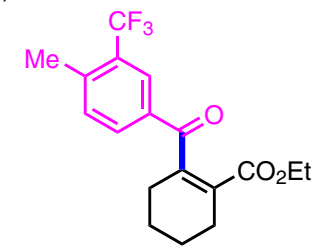

3z, $40 \%$

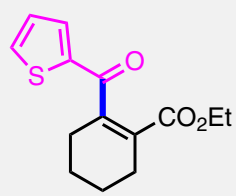

3ee, $71 \%$

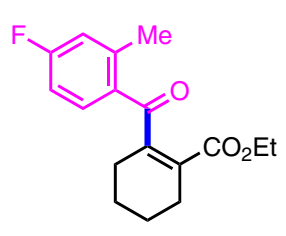

3aa, $70 \%$

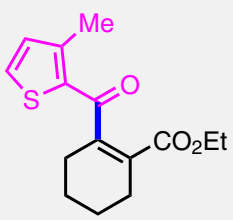

3ff, $40 \%$

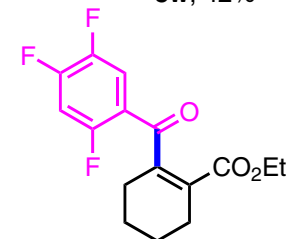

3bb, $62 \%$

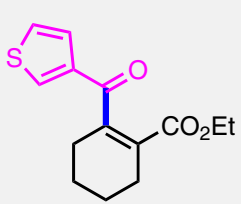

3gg, $68 \%$ 3r, $77 \%$<smiles>CCOC(=O)C1=C(C(=O)c2ccc3c(c2)OCO3)CCCC1</smiles>

3x, $70 \%$

Fig. 2 Scope of aromatic acids. Standard conditions: PC-1 (1 mol\%), Ni(COD)(DQ) (3 mol\%), $\mathbf{L}$ ( $5 \mathrm{~mol} \%), \mathbf{1 a}(0.2 \mathrm{mmol}), \mathbf{2 a}(0.3 \mathrm{mmol}), \mathrm{Ph} 3 \mathrm{P}$ $(0.3 \mathrm{mmol}), \mathrm{Na}_{2} \mathrm{CO}_{3}(0.4 \mathrm{mmol}), \mathrm{DMF}(3.5 \mathrm{~mL})$, blue LEDs, under air, ambient temperature, $24 \mathrm{~h}$. Isolated yields.

proved to be ineffective for this transformation (entry 4). When the solvent was changed from DMF to MeCN, DCM or THF, the yield of target product (3a) significantly decreased (entries 5-7), probably as the inorganic base can dissolve better in DMF to promote the reaction process. The use of $\mathrm{Cs}_{2} \mathrm{CO}_{3}$ as the base also compromised the reaction efficiency (entry 8). Control experiments demonstrated that photocatalyst, nickel catalyst, $\mathrm{Ph}_{3} \mathrm{P}$ and light were all necessary for the reaction to occur (entry 9).

Substrate scope. With the standard conditions in hand and using ethyl 2-(((trifluoromethyl)sulfonyl)-oxy)cyclohex-1-ene-1-carboxylate (2a) as a coupling partner, a wide range of aromatic carboxylic acids were investigated, and the results shown in Fig. 2 were obtained. Aromatic acids with one para-substituent on the phenyl group were found to produce the desired product (3a-3k) with satisfactory yields. A series of versatile functional group substituents, such as -methylthio, -benzyloxy, and - hydroxymethyl are tolerated well under the optimized reaction conditions, and aromatic acids bearing electron-withdrawing or electron-donating groups at the meta- or ortho-position delivered the desired products (31-3t) in moderate to good yields. A series of useful functional groups, such as reactive carbonyl (3n, 3o, 3q) and cyano groups (3r) are also compatible. Significantly, multi-substituted carboxylic acids do not detract from the reaction efficiency, giving rise to the desired products $(\mathbf{3 u}-\mathbf{3 b b})$ in synthetically useful yields. Heteroaromatic carboxylic acids engage in this $\mathrm{C}-\mathrm{C}$ coupling process successfully, producing desired the tetrasubstituted alkenes (3cc-3hh) in $40-71 \%$ yields.

Subsequently we explored the scope of the enol triflates (Fig. 3). Generally, the ester substituents on the six membered rings may have negligible influence of the transformation and deliver the 


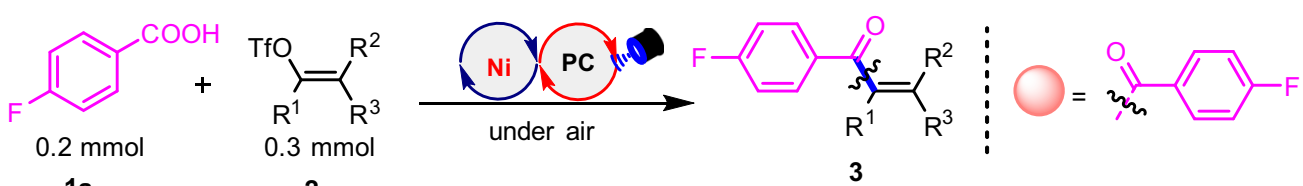

$1 \mathrm{a}$

2<smiles>COC(OC)C1=C(CO)CCOC1</smiles>

3ii, $63 \%$<smiles>CCOC(=O)C1=C(c2ccccc2)CCC1</smiles>

$300,40 \%^{a, b}$

$\overbrace{\mathrm{Me}}^{\mathrm{CO}_{2} \mathrm{Et}}$<smiles>CCOC(=O)C1=C(c2ccccc2)CCC(c2ccccc2)C1</smiles>

3jj, 75\%<smiles>COC(=O)C1=C(C(=O)OC)CCCC1</smiles>

3pp, $76 \%^{\mathrm{a}}$<smiles>CCOC(=O)C1=C(C2CCCC2)CCC(F)(F)C1</smiles>

3kk, $65 \%$<smiles>CC1=C(O)CCCC1=O</smiles>

3II, $30 \%$

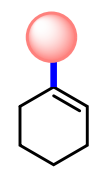

$3 \mathrm{~mm}, 85 \%$<smiles>CC(O)=C1CCCCC1O</smiles>

$3 n n, 70 \%$

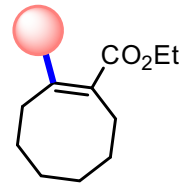

3qq, $74 \%^{\text {a }}$<smiles>CCCC1=C(C(=O)OCC)CCCCCCCCCC1</smiles>
$3 \mathrm{rr}, 57 \%$

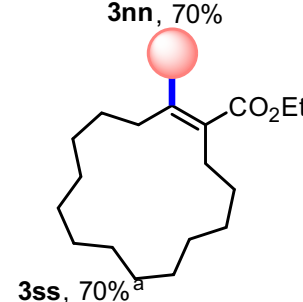

3ss, $70 \%$<smiles>C=CC/C(C(=O)OCC)=C(\C)c1ccccc1</smiles>

$3 w w, 30 \%, Z / E>20: 1^{a}$<smiles>CCOC(=O)C(Cc1ccccc1)=C(C)CC</smiles>

3tt, $60 \%, Z / E>20: 1^{\text {a }} 3$ uu, $35 \%, Z I E>20: 1^{\text {a }}$

$3 v v, 53 \%, Z / E>20: 1^{a}$

$3 x x, 65 \%, Z / E>20: 1^{a}$<smiles>CCCCCC1=C(C(=O)O[C@@H]2C[C@H](C)CC[C@@H]2C(C)C)CCCC1</smiles>

from $L$-Menthol

3yy, $78 \%$

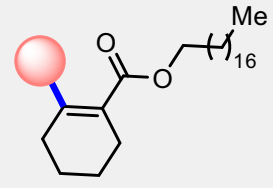

from 1-Octadecanol 3zz, $74 \%$ complex vinyl triflates

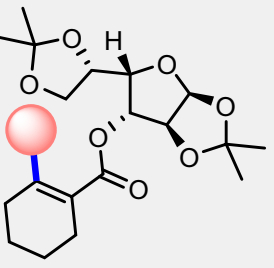

from Diacetone-D-glucose 3AA, $72 \%$
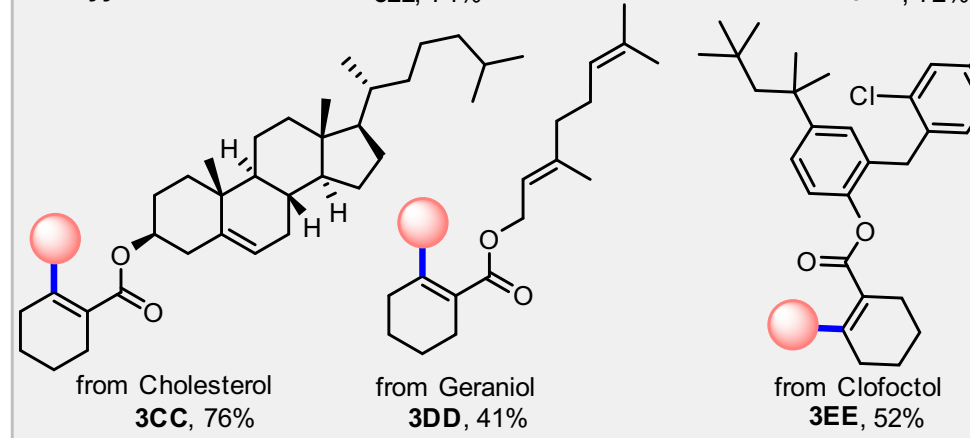

$\mathrm{Cl}$

\section{from D-galactopyranose} 3BB, $82 \%$

Fig. 3 Scope of alkenyl triflates. Standard conditions: PC-1 (1 mol\%), Ni(COD)(DQ) (3 mol\%), L1 (5 mol\%), 1 a $(0.2 \mathrm{mmol}), 2(0.3 \mathrm{mmol}), \mathrm{Ph} 3 \mathrm{P}$

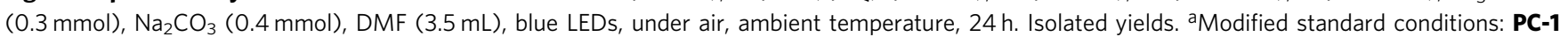
(2 mol\%), Ni(COD)(DQ) (6 mol\%), L1 (10 mol\%), 1a $(0.2 \mathrm{mmol}), 2(0.3 \mathrm{mmol}), \mathrm{Ph}_{3} \mathrm{P}(0.3 \mathrm{mmol}), \mathrm{Cs}_{2} \mathrm{CO}_{3}(0.3 \mathrm{mmol}), \mathrm{DMF}(3.5 \mathrm{~mL}), \mathrm{blue} \mathrm{LEDs}, \mathrm{under}$ air, ambient temperature, $24 \mathrm{~h}$, isolated yields. ${ }^{b} 0.4$ mmol $\mathrm{K}_{2} \mathrm{CO}_{3}$ instead of $\mathrm{Cs}_{2} \mathrm{CO}_{3}$.

products (3ii-3kk). When there is a methyl substituent on the side chain, as in 311, the yield declines to $30 \%$. It was envisioned that the ester group could play a role in the stabilization of the transition-state with coordination to the nickel center. The reaction is also suitable for the synthesis of trisubstituted alkenes in good yield $(\mathbf{3 m m})$. We envisioned that the trisubstituted alkene is likely to be less congested than tetrasubstituted alkene, where the chelation stabilization of ester group is not vital. The replacement of the carboethoxy group in the ester unit with a carbomethoxy group delivered the product (3nn) in $70 \%$ yield. In addition to six membered rings, other kinds of rings bearing alkenyl triflates react well. For example, the five-membered alkenyl triflate can undergo this $\mathrm{C}-\mathrm{C}$ cross-coupling in moderate yield (3oo). Alkenyl triflates derived from 7-, 8-, 12-, or 15membered cyclic ketones, can uniformly undergo this transformation to afford the desired products (3pp-3ss) in $57-76 \%$ yields. When acyclic alkenyl triflates were subjected to this protocol, the desired linear all-carbon tetrasubstituted alkenes $(\mathbf{3 t t}-\mathbf{3 x x})$ were obtained in moderate yields and with excellent $Z / E$ stereoselectivity. The stereochemistry of the alkenyl triflate starting materials is reliably translated into the products. Interestingly, it was found that the tetramethylsilyl group and terminal alkenes remain intact during the coupling (3vv, 3ww). To demonstrate the inherent value of the methodology, the strategy was applied to the 


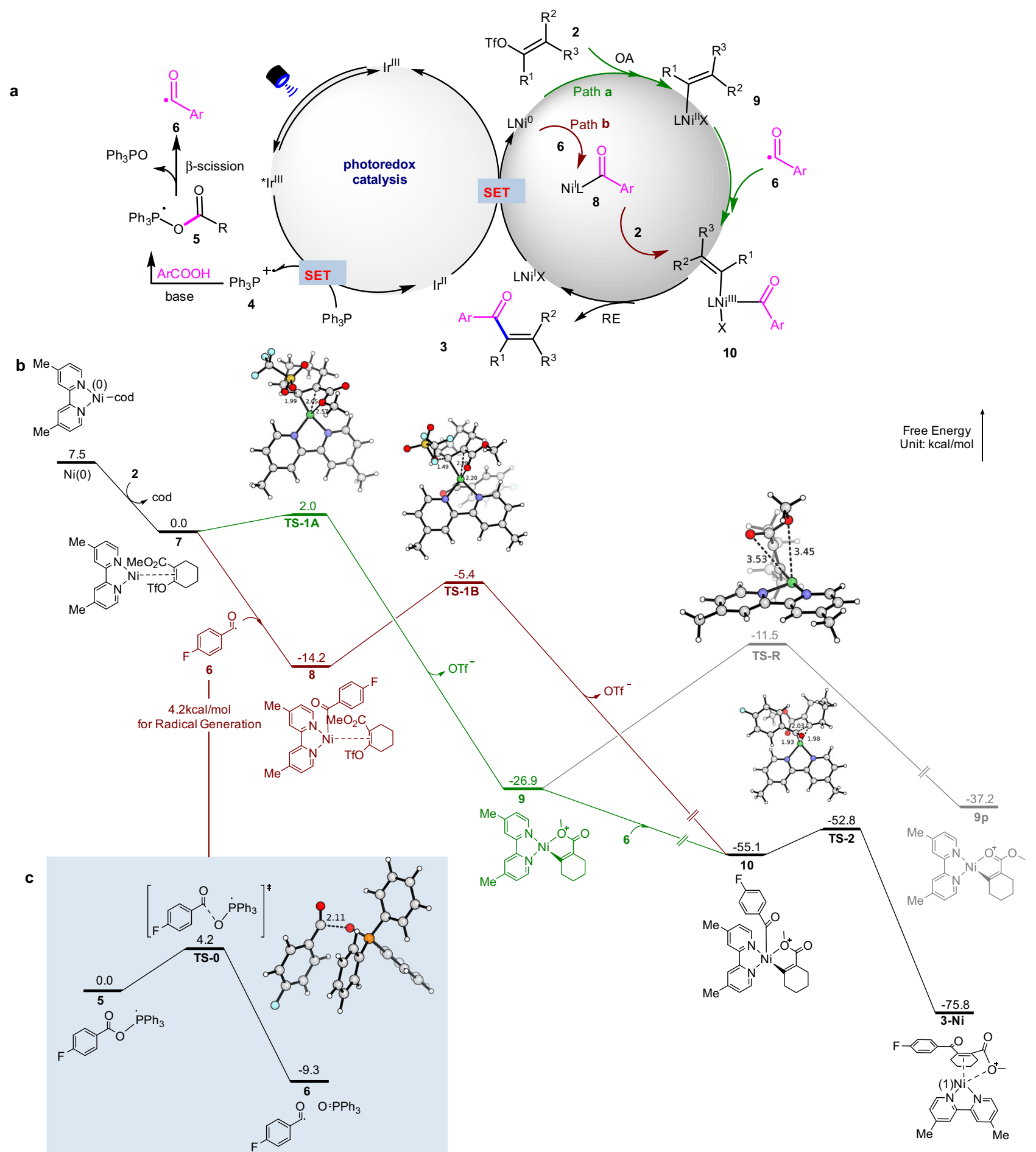

PBE0-D3/def2-TZVP/SMD(DMF)//PBE0-D3/def2-SVP/SMD(DMF)

Fig. 4 Mechanistic studies. a Proposed mechanism. b DFT calculation results. PES of the reaction with $\mathbf{7}$ as the reference point (radical coupling is barrierless confirmed by scan study, see details in SI.). c PES of the reaction with $\mathbf{5}$ as the reference point.

construction of a series of complex all-carbon tetrasubstituted alkenes (3yy-3FF). Many complex alkenyl triflates bearing different functional groups tolerate the conditions well, affording a series of structurally diverse all-carbon substituted alkenes in satisfying yields of $41-82 \%$ under air atmosphere conditions.

Mechanistic studies. Two possible dual catalytic mechanisms are depicted in Fig. $4 \mathrm{a}^{20-38}$. Firstly, under blue light irradiation, photo-excited ${ }^{*}\left[\operatorname{Ir}\left(\mathrm{dF}\left(\mathrm{CF}_{3}\right) \mathrm{ppy}_{2}(\mathrm{dtbbpy})\right] \mathrm{PF}_{6} \quad{ }^{1 / 2} E_{\text {red }} \quad\left({ }^{*} \operatorname{Ir}{ }^{\mathrm{III}} /\right.\right.$
$\left.\mathrm{Ir}^{\mathrm{II}}\right)=+1.21 \mathrm{~V}$ vs $\left.\mathrm{SCE}=2.3 \tau=2.3 \mu \mathrm{s}\right]^{45}$ can be generated, and is able to undergo a single electron oxidation with $\mathrm{PPh}_{3}$ to generate a phosphoryl radical $(4)^{42}$. In the presence of base, the resultant carboxylate anion would recombine with the phosphoryl radical (4) to produce the key intermediate (5), which can generate an acyl radical (6) via $\mathrm{C}-\mathrm{O}$ homolysis ${ }^{46}$. Meanwhile, the alkenyl triflate (2) would undergo oxidative addition with $\mathrm{L}_{\mathrm{n}} \mathrm{Ni}(0)$ to produce the (alkenyl) Ni(II) complex (9), which can be intercepted by the resulting acyl radical $(\mathbf{6})$, to produce a $\mathrm{Ni}(\mathrm{III})$ 
species (path a). In an alternative mechanistic pathway (path b), the acyl radical (6) is captured by $\mathrm{Ni}(0)$, forming an acylnickel(I) intermediate (8) prior to oxidative addition to 2 , forming the $\mathrm{Ni}(\mathrm{III})$-intermediate (10). The reductive elimination of this $\mathrm{Ni}(\mathrm{III})$-intermediate (10) would deliver the desired product (3). Concurrently, single-electron transfer from $\mathrm{Ir}(\mathrm{II})$ to the $\mathrm{Ni}(\mathrm{I})$ regenerated both $\mathbf{P C}-\mathbf{1}$ and $\mathrm{Ni}(0)$, completing both catalytic cycles.

The main difference between path $\mathbf{a}$ and path $\mathbf{b}$ is that either $\mathrm{Ni}(0)$ or $\mathrm{Ni}(\mathrm{I})$ is acting as the active species and DFT calculations were conducted to shed light on this question (Fig. 4b). Based on the energy profile calculated at the level of PBE0-D3/def2-TZVP/ $\mathrm{SMD}(\mathrm{DMF}) / / \mathrm{PBE} 0-\mathrm{D} 3 /$ def2-SVP/SMD (DMF) in Fig. 4b, once the acyl radical (6) is formed, it could be captured rapidly in a barrierless manner to give $\mathrm{Ni}(\mathrm{I})$ (Path $\mathbf{b}$ ). But the generation of the acyl radical (6) should be slower than the oxidative addition (OA) (path a) according to the computed barriers $\left(\Delta \mathrm{G}^{\neq}=4.2 \mathrm{kcal} / \mathrm{mol}\right.$ vs $2.0 \mathrm{kcal} / \mathrm{mol})$. Accordingly, the $\mathrm{Ni}(0)$ will be converted to $\mathrm{Ni}(\mathrm{II})(\mathbf{9})$ before any radical is formed. As a result, the reaction goes through path $\mathbf{a}$ as the radical generation loses the competition with the $\mathrm{Ni}(0)$ oxidative addition.

The shape of the potential energy surface (PES) in Fig. $4 \mathrm{~b}$ is commonly observed in this type of catalysis that consists of $\mathrm{Ni}(0)$ and a radical ${ }^{47-50}$. The oxidative addition barrier of $\mathrm{Ni}(\mathrm{I})$ is consistently significantly lower than the oxidative addition barrier of $\mathrm{Ni}(0)$, and is always limited by the concentration of the radical. This renders the determination of the preferred pathway difficult ${ }^{47-50}$. Our DFT results provide a strategy for this type of reaction by comparing the $\mathrm{Ni}(0)$ oxidative addition barrier with the overall barrier of radical generation. In our case, the $\mathrm{Ni}(0)$ oxidative addition barrier is low enough that the higher barrier is associated with the radical generation. This small barrier for a crowded transition state is a result of the neighboring ester group stabilization $\left(\mathrm{d}_{\mathrm{O}} \ldots \mathrm{Ni}\right.$,TS-A $\left.=2.57 \AA\right)$, which is sterically infeasible in the reactant.

In those TSs (TS-1A and TS-1B) of oxidative addition (OA), an $\mathrm{S}_{\mathrm{N}} 2^{\prime}$-like process is observed. The $\mathrm{O}$-atom in ester moiety attacks the $\mathrm{Ni}$ center and pushes the electron to the middle carbon which then kicks off the -OTf as a leaving group, resulting in the formation of a chelated product 9 or 10. With 9 formed by the favorable path a, a competition exists between isomerization into a more stable $9 p$ and recombination with free acyl radical 6. The energy barrier of the former is $15.4 \mathrm{kcal} \mathrm{mol}^{-1}$, which is higher than the estimated barrier of the radical generation $\left(4.2 \mathrm{kcal} \mathrm{mol}^{-1}\right)$. Therefore, before the isomerization of 9 , there will be sufficient concentration of acyl radicals to complete the radical addition and irreversibly produces the pentacoordinate $\mathbf{1 0}$ (See Supplementary Information for detailed discussion of the active species for radical addition among $\mathrm{Ni}(\mathrm{II})$ isomers, including a more comprehensive PES with the potential OTf coordination). The final reductive elimination TS-2 has a low barrier of $2.3 \mathrm{kcal} \mathrm{mol}^{-1}$ that gives the final product swiftly. The mechanistic control experiments (Supplementary Fig. 13) also suggest that the radical addition to $\mathrm{Ni}(0)$ is less likely (Path b).

Synthetic application. With this possible mechanistic understanding of this coupling reactions, we explored its synthetic applications (Fig. 5). As shown in Fig. 5a, we developed a one-pot, two-step strategy for the concise synthesis of all-carbon tetrasubstituted alkenes directly from ketones. In addition, this protocol was found to be easily used at the gram scale (Fig. 5b). Interestingly, when indole-based aromatic acid (12) was subjected to this protocol, it can undergo a tandem $\mathrm{C}$ - $\mathrm{C}$ coupling and subsequent Nazarov cyclization to afford product (13) in $70 \%$ yield. The structure of 13 was confirmed by X-ray single crystal analysis

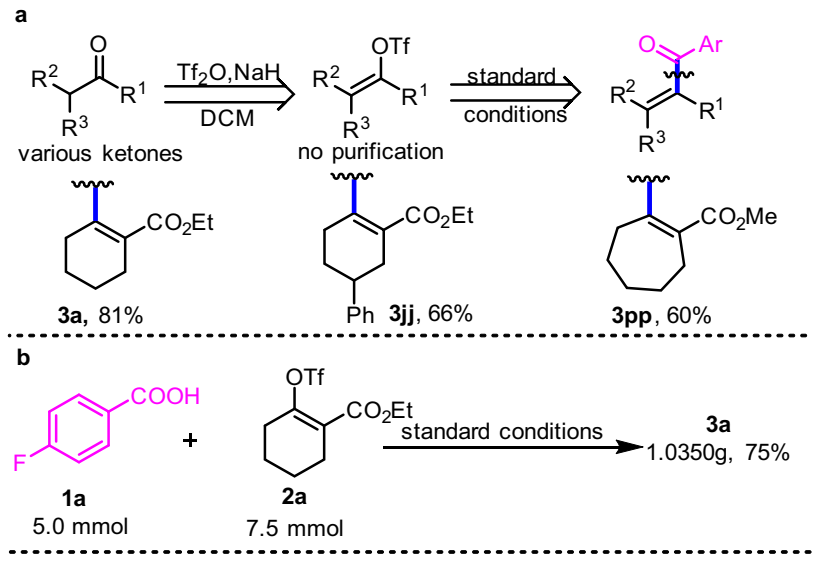

c

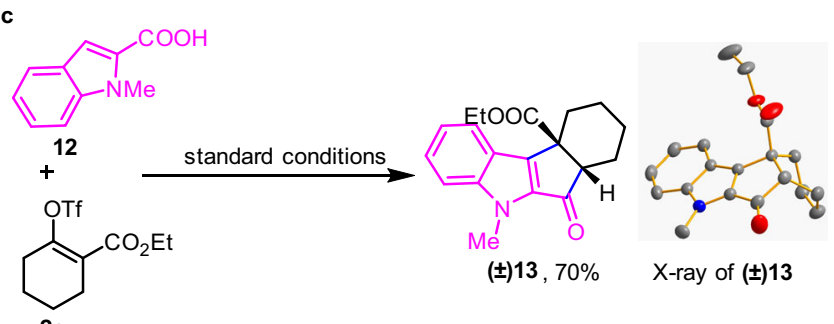

$2 a$

d

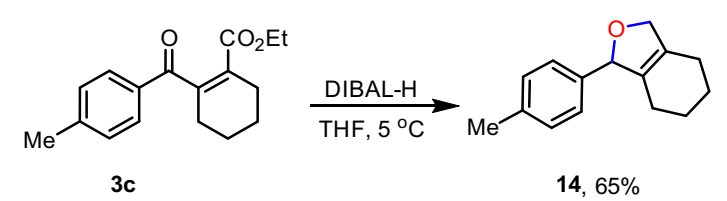

Fig. 5 Synthetic application. a one-pot two-steps synthesis of $\mathbf{3}$. b Gramscale experiment. c Tandem C-C coupling/Nazarov cyclization. d Reduction of $3 c$.

(Fig. 5c). Interestingly, reduction of product 3c with diisobutylaluminium hydride (DIBAL-H) can directly lead to all-carbon tetrasubstituted alkenes, hexahydroisobenzofuran product $\mathbf{1 4}$ (Fig. 5d).

\section{Discussion}

We have developed a strategy for the synthesis of all-carbon tetrasubstituted alkenes via synergistic photoredox/nickel catalysis under an air atmosphere. A large number of readily available aromatic acids and alkenyl triflates are efficient coupling partners in this $\mathrm{C}-\mathrm{C}$ coupling, affording a rich library of structurally diverse acyclic and cyclic all-carbon tetrasubstituted alkenes in moderate to good yields and with excellent $Z / E$ stereoselectivity. DFT calculations indicate that this transformation may proceed via a $\mathrm{Ni}(0) / \mathrm{Ni}(\mathrm{II}) / \mathrm{Ni}(\mathrm{III})$ pathway. This protocol can avoid the utilization of moisture-sensitive organometallic reagents and the need for an inert gas atmosphere, greatly simplifying the operation of metallophotoredox reactions with $\mathrm{Ni}(0)$ catalysis. This is also an important advance in the synthesis of all-carbon tetrasubstituted alkenes from readily available feedstock chemicals.

\section{Methods}

General procedure for the synthesis of all-carbon tetrasubstituted alkenes. Under air atmosphere, a stirring bar, $\mathrm{Ni}(\mathrm{COD})(\mathrm{DQ})(3.0 \mathrm{~mol} \%), 4,4^{\prime}$-di-methylbutyl-2,2'-bipyridine $(5.0 \mathrm{~mol} \%)$, and DMF $(2.0 \mathrm{~mL})$ were successively added to a vial $(2.0 \mathrm{~mL})$. The vial was stirred until the resulting mixture become homogeneous (about $20 \mathrm{~min}$ ). Subsequently, photocatalyst $\operatorname{Ir}\left[\mathrm{dF}\left(\mathrm{CF}_{3}\right) \mathrm{ppy}\right]_{2}(\mathrm{dtbbpy}) \mathrm{PF}_{6}(1 \mathrm{~mol} \%)$, aromatic carboxylic acid ( $0.2 \mathrm{mmol}, 1.0$ equiv), triflates ( $0.3 \mathrm{mmol}, 1.5$ equiv), $\mathrm{Ph}_{3} \mathrm{P}$ ( $0.3 \mathrm{mmol}, 1.5$ equiv), and $\mathrm{Na}_{2} \mathrm{CO}_{3}(0.4 \mathrm{mmol}, 2.0$ equiv) were added to an $3.5 \mathrm{~mL}$ screw-cap vial equipped with a magnetic stirring bar. The resulting homogenous solution was syringed into the vial. Then DMF $(1.5 \mathrm{~mL})$ was added into the vial. The vial was sealed and placed $\sim 5 \mathrm{~cm}$ blue LEDs. The reaction mixture was stirred for 
$24 \mathrm{~h}$ at room temperature (air conditions were used to keep the temperature is $25^{\circ} \mathrm{C}$ or so). After reaction completion, the reaction mixture was removed from the light. The solvent was removed and the residue was purified by flash chromatography on silica gel to afford the corresponding products.

\section{Data availability}

The authors declare that all other data supporting the findings of this study are available within the article and Supplementary Information files, and also are available from the corresponding author. The X-ray crystallographic data of product $\mathbf{1 3}$ in this study has been deposited in the Cambridge Crystallographic Data Centre under accession code CCDC 2089722.

Received: 16 July 2021; Accepted: 14 November 2021;

Published online: 04 February 2022

\section{References}

1. Flynn, A. B. \& Ogilvie, W. W. Stereocontrolled synthesis of tetrasubstituted olefins. Chem. Rev. 107, 4698-4745 (2007).

2. Maryanof, B. E. \& Reitz, A. B. The wittig olefination reaction and modifications involving phosphoryl-stabilized carbanions. Stereochemistry, mechanism, and selected synthetic aspects. Chem. Rev. 89, 863-927 (1989).

3. Ager, D. J. in Organic Reactions Vol. 38 (Wiley, 1990)

4. Kelly, S. E. Comprehensive Organic Synthesis (Elsevier, 1991).

5. Takeda, T. (ed.) Modern Carbonyl Olefination (Wiley, 2004).

6. Li, B.-J. et al. Cross-coupling of alkenyl/aryl carboxylates with Grignard reagent via Fe-catalyzed C-O bond activation. J. Am. Chem. Soc. 131, 14656-14657 (2009).

7. Ackermann, L., Kapdi, A. R., Fenner, S., Kornhaass, C. \& Schulzke, C. Welldefined air-stable palladium HASPO complexes for efficient Kumada-Corriu cross-couplings of (hetero)aryl or alkenyl tosylates. Chem. Eur. J. 17, 2965-2971 (2011).

8. Wong, P. Y. et al. A versatile palladium catalyst system for Suzuki-Miyaura coupling of alkenyl tosylates and mesylates. Chem. Commun. 47, 8328-8330 (2011).

9. Zou, Y. et al. Selective arylation and vinylation at the $\alpha$-position of vinylarenes. Chem. Eur. J. 19, 3504-3511 (2013).

10. Gartner, D., Stein, A. L., Grupe, S., Arp, J. \& Jacobi von Wangelin, A. Ironcatalyzed cross-coupling of alkenyl acetates. Angew. Chem. Int. Ed. 54, 10545-10549 (2015).

11. Rivera, A. C., Still, R. \& Frantz, D. E. Iron-catalyzed stereoselective crosscoupling reactions of stereodefined enol carbamates with Grignard reagents. Angew. Chem. Int. Ed. 55, 6689-6693 (2016).

12. Li, B. X. et al. Highly stereoselective synthesis of tetrasubstituted acyclic allcarbon olefins via enol tosylation and Suzuki-Miyaura coupling. J. Am. Chem. Soc. 139, 10777-10783 (2017).

13. Li, J. \& Knochel, P. Cobalt-catalyzed cross-couplings between alkenyl acetates and aryl or alkenyl zinc pivalates. Angew. Chem. Int. Ed. 57, 11436-11440 (2018).

14. Olivares, A. M. \& Weix, D. J. Multimetallic Ni- and Pd-catalyzed crosselectrophile coupling to form highly substituted 1,3-dienes. J. Am. Chem. Soc. 140, 2446-2449 (2018).

15. Li, J., Ren, Q., Cheng, X., Karaghiosoff, K. \& Knochel, P. Chromium(II)catalyzed diastereoselective and chemoselective Csp2-Csp3 cross-couplings using organomagnesium reagents. J. Am. Chem. Soc. 141, 18127-18135 (2019).

16. Li, W., Yu, S., Li, J. \& Zhao, Y. Nickel-catalyzed allylmethylation of alkynes with allylic alcohols and AlMe3: facile access to skipped dienes and trienes. Angew. Chem. Int. Ed. 59, 14404-14408 (2020).

17. Schreib, B. S., Fadel, M. \& Carreira, E. M. Palladium-catalyzed C-H alkynylation of unactivated alkenes. Angew. Chem. Int. Ed. 59, 7818-7822 (2020).

18. Tellis, J. C., Primer, D. N. \& Molander, G. A. Single-electron transmetalation in organoboron cross-coupling by photoredox/nickel dual catalysis. Science 345, 433-436 (2014)

19. Zuo, Z. et al. Merging photoredox with nickel catalysis: coupling of $\alpha$-carboxyl sp3-carbons with aryl halides. Science 345, 437-440 (2014)

20. Gutierrez, O., Tellis, J. C., Primer, D. N., Molander, G. A. \& Kozlowski, M. C. Nickel-catalyzed cross-coupling of photoredox-generated radicals: uncovering a general manifold for stereoconvergence in nickel-catalyzed cross-couplings. J. Am. Chem. Soc. 137, 4896-4899 (2015).

21. Zhang, L. \& Hashmi, A. S. K. The combination of benzaldehyde and nickelcatalyzed photoredox Halkylation/arylation. Angew. Chem. Int. Ed. 58, 1823-1827 (2019).

22. Terrett, J. A., Cuthbertson, J. D., Shurtleff, V. W. \& MacMillan, D. W. Switching on elusive organometallic mechanisms with photoredox catalysis. Nature 524, 330-334 (2015).
23. Yamashita, Y., Tellis, J. C. \& Molander, G. A. Protecting group-free, selective crosscoupling of alkyltrifluoroborates with borylated aryl bromides via photoredox/ nickel dual catalysis. Proc. Natl Acad. Sci. USA 112, 12026-12029 (2015).

24. Si, X., Zhang, L. \& Hashmi, A. S. K. Benzaldehyde- and nickel-catalyzed photoredox $\mathrm{C}(\mathrm{sp} 3)-\mathrm{H}$ alkylation/arylation with amides and thioethers. Org Lett. 21, 6329-6332 (2019).

25. Yue, H., Zhu, C. \& Rueping, M. Cross-coupling of sodium sulfinates with aryl, heteroaryl, and vinyl halides by nickel/photoredox dual catalysis. Angew. Chem. Int. Ed. 57, 1371-1375 (2018).

26. Cheng, X., Lu, H. \& Lu, Z. Enantioselective benzylic C-H arylation via photoredox and nickel dual catalysis. Nat. Commun. 10, 3549 (2019).

27. Dewanji, A., Krach, P. E. \& Rueping, M. The dual role of benzophenone in visible-light/nickel photoredox-catalyzed $\mathrm{C}-\mathrm{H}$ arylations: hydrogen-atom transfer and energy transfer. Angew. Chem. Int. Ed. 58, 3566-3570 (2019).

28. Gandolfo, E., Tang, X., Raha Roy, S. \& Melchiorre, P. Photochemical asymmetric nickel-catalyzed acyl cross-coupling. Angew. Chem. Int. Ed. 58, 16854-16858 (2019)

29. Garcia-Dominguez, A., Mondal, R. \& Nevado, C. Dual photoredox/nickelcatalyzed three-component carbofunctionalization of alkenes. Angew. Chem. Int. Ed. 58, 12286-12290 (2019)

30. Milligan, J. A., Phelan, J. P., Badir, S. O. \& Molander, G. A. Alkyl carboncarbon bond formation by nickel/photoredox cross-coupling. Angew. Chem. Int. Ed. 58, 6152-6163 (2019).

31. Zhang, L. et al. The combination of benzaldehyde and nickel-catalyzed photoredox C(sp3)-H alkylation/arylation. Angew. Chem. Int. Ed. 58, 1823-1827 (2019).

32. Zhu, C. et al. A multicomponent synthesis of stereodefined olefins via nickel catalysis and single electron/triplet energy transfer. Nat. Catal. 2, 678-687 (2019).

33. Fan, P., Lan, Y., Zhang, C. \& Wang, C. Nickel/photo-cocatalyzed asymmetric acyl-carbamoylation of alkenes. J. Am. Chem. Soc. 142, 2180-2186 (2020)

34. Guan, H., Zhang, Q., Walsh, P. J. \& Mao, J. Nickel/photoredox-catalyzed asymmetric reductive cross-coupling of racemic a-chloro esters with aryl iodides. Angew. Chem. Int. Ed. 59, 5172-5177 (2020)

35. Mega, R. S., Duong, V. K., Noble, A. \& Aggarwal, V. K. Decarboxylative conjunctive cross-coupling of vinyl boronic esters using metallaphotoredox catalysis. Angew. Chem. Int. Ed. 59, 4375-4379 (2020).

36. Song, F. et al. Visible-light-enabled stereodivergent synthesis of E- and Z-configured 1,4-dienes by photoredox/nickel dual catalysis. Angew. Chem. Int. Ed. 59, 177-181 (2020).

37. Zhang, Y., Wang, X.-C., Ju, C.-W. \& Zhao, D. Bis-silylation of internal alkynes enabled by $\mathrm{Ni}(0)$ catalysis. Nat. Commun. 12, 68 (2021)

38. Zhu, C., Yue, H., Chu, L. \& Rueping, M. Recent advances in photoredox and nickel dual-catalyzed cascade reactions: pushing the boundaries of complexity. Chem. Sci. 11, 4051-4064 (2020).

39. Ruzi, R., Liu, K., Zhu, C. \& Xie, J. Upgrading ketone synthesis direct from carboxylic acids and organohalides. Nat. Commun. 11, 3312 (2020).

40. Nattmann, L., Saeb, R., Nöthling, N. \& Cornella, J. An air-stable binary $\mathrm{Ni}(0)-$ olefin catalyst. Nat. Catal. 3, 6-13 (2019).

41. Tran, V. T. et al. Ni(COD)(DQ): an air-stable 18-electron nickel(0)-olefin precatalyst. Angew. Chem. Int. Ed. 59, 7409-7413 (2020).

42. Zhang, M., Xie, J. \& Zhu, C. A general deoxygenation approach for synthesis of ketones from aromatic carboxylic acids and alkenes. Nat. Commun. 9, 3517 (2018).

43. Zhang, M., Yuan, X. A., Zhu, C. \& Xie, J. Deoxygenative deuteration of carboxylic acids with D2O. Angew. Chem. Int. Ed. 58, 312-316 (2019)

44. Stache, E. E., Ertel, A. B., Rovis, T. \& Doyle, A. G. Generation of phosphoranyl radicals via photoredox catalysis enables voltage-independent activation of strong C-O bonds. ACS Catal. 8, 11134-11139 (2018).

45. Prier, C. K., Rankic, D. A. \& MacMillan, D. W. Visible light photoredox catalysis with transition metal complexes: applications in organic synthesis. Chem. Rev. 113, 5322-5363 (2013).

46. Schiavon, G., Zecchin, S. \& Cogoni, G. Anodic oxidation of triphenylphosphine at a platinum electrode in acetonitrile medium. J. Electroanal. Chem. Interfacial Electrochem. 48, 425-431 (1973).

47. Qi, Z.-H. \& Ma, J. Dual role of a photocatalyst: generation of $\mathrm{Ni}(0)$ catalys and promotion of catalytic C-N bond formation. ACS Catal. 8, 1456-1463 (2018).

48. Guo, L. et al. General method for enantioselective three-component carboarylation of alkenes enabled by visible-light dual photoredox/nickel catalysis. J. Am. Chem. Soc. 142, 20390-20399 (2020).

49. Maity, B. et al. Mechanistic insight into the photoredox-nickel-HAT triple catalyzed arylation and alkylation of a-amino Csp3-H bonds. J. Am. Chem. Soc. 142, 16942-16952 (2020).

50. Yuan, M., Song, Z., Badir, S. O., Molander, G. A. \& Gutierrez, O. On the nature of $\mathrm{C}(\mathrm{sp} 3)-\mathrm{C}(\mathrm{sp} 2)$ bond formation in nickel-catalyzed tertiary radical cross-couplings: a case study of $\mathrm{Ni}$ /photoredox catalytic crosscoupling of alkyl radicals and aryl halides. J. Am. Chem. Soc. 142, 7225-7234 (2020). 


\section{Acknowledgements}

We thank the National Natural Science Foundation of China (22122103, 22122104, 21971108, 21971111, 21933004, and 21702098), the National Key Research and Development Program of China (2021YFC2101901), the Natural Science Foundation of Jiangsu Province (Grant No. BK20190006), Fundamental Research Funds for the Central Universities (020514380252), "Innovation \& Entrepreneurship Talents Plan" of Jiangsu Province, the national undergraduate innovation and entrepreneurship training program, the research projects for higher education reform in Jiangsu Province (2021JSJG027), and Foundation of Advanced Catalytic Engineering Research Center of the Ministry of Education. Nian Li, Yijie He, and Shuaishuai Wang are warmly acknowledged to reproduce experimental procedures for products $\mathbf{3 a}, \mathbf{3 x x}$, and $\mathbf{3 p}$.

\section{Author contributions}

J.X. and Y.L. conceived and designed the project. Y.L. performed and analyzed the experimental data. H.H. analyzed the experimental data. Q.S. and X.-S.X. performed the DFT calculations. J.X. and C.Z. wrote the manuscript with input from all authors.

\section{Competing interests}

The authors declare no competing interests.

\section{Additional information}

Supplementary information The online version contains supplementary material available at https://doi.org/10.1038/s41467-021-27507-x.
Correspondence and requests for materials should be addressed to Chengjian Zhu, XiaoSong Xue or Jin Xie.

Peer review information Nature Communications thanks Dong Xue and the anonymous reviewer(s) for their contribution to the peer review of this work.

Reprints and permission information is available at http://www.nature.com/reprints

Publisher's note Springer Nature remains neutral with regard to jurisdictional claims in published maps and institutional affiliations.

(c) (i) Open Access This article is licensed under a Creative Commons Attribution 4.0 International License, which permits use, sharing, adaptation, distribution and reproduction in any medium or format, as long as you give appropriate credit to the original author(s) and the source, provide a link to the Creative Commons license, and indicate if changes were made. The images or other third party material in this article are included in the article's Creative Commons license, unless indicated otherwise in a credit line to the material. If material is not included in the article's Creative Commons license and your intended use is not permitted by statutory regulation or exceeds the permitted use, you will need to obtain permission directly from the copyright holder. To view a copy of this license, visit http://creativecommons.org/ licenses/by/4.0/.

(C) The Author(s) 2022 